\title{
INTERVENÇÃO PSICOPEDAGÓGICA NO TOCANTE À INDISCIPLINA EM SALA DE AULA
}

\author{
Wolly de Sousa Santos ${ }^{1}$
}

RESUMO: No mundo globalizado de hoje, a grande preocupação das escolas é com a Indisciplina que vem levando vários docentes a uma reflexão constante sobre suas origens, consequências e posteriores soluções. Visto que, esta perpassa em todas as escolas do Brasil e do mundo a fora, faz de uma sala de aula, de uma escola local, difícil de ensinar e propagar o conhecimento. Há muito se fala, mas pouco se investe em soluções. Manter uma constante em sala de aula com os discentes produtivos, tanto quantitativos, quanto qualitativos têm levado vários doutores, mestres e graduados na área da educação, a buscarem meios que deem soluções ou amenizem esta situação periclitante, crescente a cada dia. Questionamentos são feitos: De quem é a culpa? Docente e/ou discente? Família e/ou escola? Que fatores acarretam à indisciplina? Assim, para melhor entendimento será abordado tanto o conceito de Disciplina como o de Indisciplina, de maneira que propiciará ao amigo leitor e um cunho contextualizado e passará entendimento contendo intervenções psicopedagógicas para vislumbre de uma sala e de uma escola, com auxílio ao diagnóstico preciso e intervenções apropriadas.

Palavras-Chave: Disciplina. Indisciplina. Docente. Discente. Família.

\section{A INDISCIPLINA EM SALA DE AULA}

Atualmente os problemas de Indisciplina na sala de aula têm prejudicado muito, fatores diversos têm contribuído, e nos faz refletir e buscar soluções urgentes. No que diz respeito a ensino-aprendizado, na maioria das vezes os docentes trazem consigo um plano de aula bem planejado, no entanto, devido às dificuldades que os discentes trazem consigo de sua vivência familiar, tornam estes impasses um ambiente escolar indisciplinado, ocasionando um declínio no ensino-aprendizado.

O que se prega na escola, um ensino e aprendizado de qualidade que possa vir a fluir com excelência, requer que os docentes criem estratégias juntamente com a coordenação escolar, para lidar com essas dificuldades deparadas na sala de aula, as

\footnotetext{
I Coordenador na rede municipal de ensino do município de Placas no estado do Pará. Mestre em Educação pela Universidade Francis Xavier, Pós-Graduado em Psicopedagogia Institucional e Clínica pela Faculdade Cerrado, Especialista em Educação Profissional e Tecnológica pelo Instituto Federal do Espirito Santo, Especialista em Gestão Escolar e Coordenação Pedagógica na Facesita, Graduado em Pedagogia e Teólogo pela Faculdade de Teologia de Boa Vista.
} 
consequências têm sido constantes, que ferramentas podemos utilizar em pertinências plausíveis? É pergunta a se fazer para que sirva de percussor com retorno vindouro.

Cuban (1992) afirma que os discentes são capazes de mudar o currículo pela forma como participam e alteram as atividades em sala. Por exemplo, os discentes instigam o docente a perder o foco de seu planejamento, que influencia em consequências grandes e pequenas nos temas a serem expostos, por conseguinte o esvaziamento de suas importâncias.

É de grande importância se observar, para que se tenha resultados positivos no tocante à indisciplina, uma investigação psicopedagógica das causas que gerou o fator indisciplina e impeça que esta se fixe nas salas de aula alterando a direção do currículo.

\section{I.I Procedimento metodológico}

O presente trabalho foi realizado a partir de pesquisas bibliográficas em revistas, livros e textos de autores diferentes ao tema trabalhado neste artigo.

\section{DISCIPLINA}

A disciplina é conquistada todos os dias, é preciso sempre lembrar as regras do jogo, cada vez é preciso reinteressá-los, cada vez é preciso ameaçar, cada vez é preciso recompensar. DUBET (1997)

Disciplina tem em sua essência valores como: "ordem, respeito e obediências às regras”, valores estes, que regem uma sala de aula, e outro qualquer ambiente disciplinado em que ambos os indivíduos que os compõem agem mutualmente com amor uns com os outros, no momento em discurso, respeito entre discente e docente, sem que uma das partes tenha que se impor de forma abrupta.

Dubet, ressalta a necessidade de os docentes relembrarem as regras e estimularem no decorrer do ano letivo. No que diz respeito à indisciplina vem consigo diversos comentários. Um discente indisciplinado é um indivíduo que está intrinsicamente contido de atitudes torpes que externa com atos contrários ao meio. $\mathrm{O}$ comportamento inadequado está relacionado a uma atitude contrário, do dito pelo docente, o mesmo não consegue motivá-lo de forma eficiente, pois há problemas familiares, carência dos pais, exposição à ídolos violentos, problemas de relacionamento interpessoal entre o docente e o discente. 
O conceito de indisciplina apresenta uma complexidade que precisa ser considerada. É preciso, por exemplo, superar a noção arcaica de indisciplina como algo restrito à dimensão comportamental. Ainda é necessário pensá-la em consonância com o momento histórico desta virada de século. (GARCIA, 1999, p. I02).

Se faz necessário, um estudo de casos relacionados à indisciplina em sala de aula, com intervenções Psicopedagógicas, no intuito de que, o docente e o discente criem vínculos afetivos para a eficiência do ensino e garanta uma qualidade no aprendizado. $\mathrm{O}$ Psicopedagogo pode ajudar a diagnosticar o problema pertinente ao aprendizado do discente, persistindo na superação das problemáticas. Por meio das ferramentas e meios metodológicos proficientes, articulando saberes nos diversos campos, o psicopedagogo atua como mediador no tocante à assimilação do conhecimento.

Requer então uma visão psicopedagógica que perpassa entre instituição escolar, “o discente" propriamente dito, sem esquecer que o meio familiar em que este passa a maior parte do tempo.

\section{I Indisciplina}

Sonhos sem disciplina produzem pessoas frustradas, e disciplina sem sonhos produz pessoas autômatas, que só sabem obedecer a ordens.

Augusto Cury

A indisciplina está presente cada vez mais no âmbito do contexto da educação familiar, é um fato real que tem se mostrado cada vez mais preocupante com declives perceptíveis no meio social. $\mathrm{Na}$ instituição escolar, a indisciplina intervém o docente no que se refere ao ensino-aprendizado, como um impasse, impossibilitando uma conquista de sucesso, no entanto, o docente tem que ter uma visão desafiadora, e este impasse servirá de degrau para uma conquista futura.

Para Aquino (1996) "muitos distúrbios disciplinares deixaram de ser um evento esporádico e particular no cotidiano escolar para se tornarem, talvez, um dos maiores obstáculos pedagógicos dos dias atuais".

Nesse contexto, grandes partes dos educadores não recebem informações, nem capacitações voltadas para a indisciplina. Segundo Freire (1921-1997): "Ninguém disciplina 


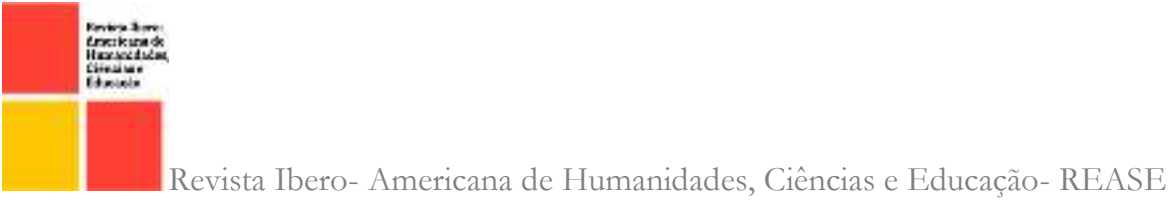

ninguém, mas por outro lado ninguém se disciplina sozinho. Os homens se disciplinam em conjunto, intermediados pela realidade do mundo".

\subsection{Anamnese no Convívio Familiar}

A “Anamnese” psicopedagógica perpassa por observações no âmbito familiar, pois, o discente tem os primeiros contatos com os valores educacionais que estão ligados por caracteres comuns a seus descendentes. Mais tarde, vem à escola, para sistematizar o conhecimento adquirido pelo meio familiar, compreendendo que a educação é vista como um processo de transformação do indivíduo. Como os pais estão colaborando com a instituição escolar para o vislumbre desse discente?

Com o passar dos anos a cultura social sofre alterações. A célula mártir da sociedade "a família" recebeu influência, não por meio natural, mas fora instigada, assim como, a comunidade escolar. Antes a instituição escolar detinha maior valor social, o docente era envolto de status, a escola tinha maior importância à família. O conhecimento era mais voltado de forma centralizada, com pouca fragmentação concomitante à realidade. Nos dias atuais, têm se distorcido, com as divisões sociais, culturais e éticas, a economia recessiva baseando-se no capitalismo e não na produção, o mérito do ter e não do ser são verdades presentes e visíveis em nosso contexto, perceptível no meio cotidiano.

O declive social pertinente se dá devido à necessidade de que, as donas do lar além de suas atribuições, se faz necessário o seu ingresso no mercado de trabalho formal provocando uma lacuna na família, lhe tomando bastante tempo de atenção dos filhos, deixando de repassar os valores de fundamental importância familiar, e acompanhar de forma profícua a vida escolar de seus filhos. Falta tempo, prioridade e motivação a estes.

A busca de instrumentos que possam auxiliar o processo de aprendizagem e desenvolvimento, no que se refere à inteligência e afetividade tem de ser veemente, pois têm se percebido em salas de aula que a falta de afetividade em seu meio familiar é que gera essa tão devastadora indisciplina em sala de aula. O discente traz consigo consequências que perpassa por longas datas, se a mesma não for diagnosticada e se buscar uma solução, terá na sociedade alguém frustado e sem limites. Por esse motivo é importante manter este vínculo de amizade escola-familia e vice-versa. 


\subsection{Intervenções Psicopedagógicas}

cabe ao Psicopedagogo o objetivo de resgatar uma visão mal globalizada do processo de aprendizagem e dos problemas desses processos. Porto (2006)

A Psicopedagogia tem seu foco na construção do conjunto de doutrinas e princípios que visam uma concepção de vida educacional adequada, ou seja, seu intuito é granjear amplo entendimento sobre os diversos seguimentos envoltos no que é tocante ao instruirse o ser humano. O que fora perdido e/ou afetado por situação degradante do meio familiar, educacional e social, é incumbência do psicopedagogo apaziguar para um melhor viver.

Partindo de observações comportamentais no rarefeito ambiente em que este indivíduo se encontra, no convívio é possível suster de argumentos que levará a detectar a lacuna exposta ao malefício que coabita para o declínio no ensino e na aprendizagem do discente e no relacionamento discente-docente.

Esta traz consigo, no seu âmago expressões mais significativas na questão do aprendizado do discente, o contexto de aprendizado do discente são compreendidos por meio de um processo abrangente, que compreende diversos campos de intervenções, tais como: afetividade, cognitividade, coordenação motora, sociais, políticos entre outros. Partindo desse princípio, as dificuldades encontradas deixam de ser exclusivamente só do docente e do discente, e permeia mais extrinsecamente, e precisam ser estudados com bastante cuidado pelo psicopedagogo.

O acompanhamento psicopedagógico com o discente que perpassa por indisciplinariedade, deverá ocorrer no cotidiano em sala de aula, e este deve permear no sentido de ajuda e de auxílio, e não na tomada de decisões definitivas. Uma observação contínua é essencial, onde o psicopedagogo irá ter um ambiente de diálogo com este discente, uma reflexão da própria avaliação dos seus resultados, condutas e práticas.

Têm-se tido em uma declaração peremptória, que cada vez mais a escola é uma instituição mais competente em aumentar o conhecimento ao discente. Afim de exercer a função de auxiliar o psicopedagogo, permeia também como auxiliador no processo de formação de um educando, visto que, este profissional está inquestionavelmente oferecendo suporte na formação e assimilação dos conteúdos, mais ainda à formação pessoal do discente. 
No ato de agir, no que diz respeito à uma indisciplina em sala de aula, o psicopedagogo intervirá como mediador, no escopo regido por levar ferramentas como: a de se construir atitudes de afetividade, aquela relação boa que deve existir entre o docente e o discente que é sujeito a desentorpecer de maneira eficaz no seguimento de educação.

O discente precisa impreterivelmente, bem como, qualquer ser humano, melindrarse como predileto, honrado e realçado, pois perpassa que no período de instrução, ele apresente atuação que transpõe seus sentimentos e comoções, contendo mais contato com vínculo de afeição, terá mais oportunidade de desenvolvimento integral.

\section{CONCLUSÃO}

Diante do exposto, sabe-se que, a indisciplina existe por vários fatores preponderantes que acarretam diversas consequências que o discente é o maior prejudicado. A família na maioria das vezes não trabalha a importância da instituição escolar, uma vez que, os próprios pais já vivem em um meio frustado, à margem da sociedade, e repassam isso para seus filhos.

Faz-se necessário, uma especial atenção voltada para a relação docente-discente, família e instituição escolar, ambos indicando alguns princípios morais que devem prevalecer no cotidiano familiar e escolar, o princípio de cooperação, com o intuito de desenvolver, nos discentes, a autonomia.

O Psicopedagogo agirá como intermediador, nas situações problemáticas, ou seja, no que diz respeito à "indisciplina", interpondo com a construção dos limites, criando vínculo de afetividade entre docente-discente e familiares, no vislumbre de uma relação que os une, que é o conhecimento.

É importante que a direção escolar faça o papel de um administrador-gestor com o objetivo de conseguir parcerias no âmbito da educação: faça implantação de inovações educacionais, desenvolva novos estudos com os discentes e consequentemente, implante estratégias de aprendizagem significativa, jamais deixando a família de lado, exercendo o todo tempo, o seu papel, sem passar a responsabilidade única e exclusiva para a escola.

Para entender os problemas de aprendizagem, faz-se necessário o diagnóstico e as intervenções, considerar os fatores tanto internos como externos do sujeito, não devendo ser ignorado as causas exógenas e endógenas, levantando assim um diagnóstico para 
procurar utilizar uma intervenção cabível. Consideramos que um dos objetivos da Psicopedagogia é a Intervenção, a fim de "colocar-se no meio", de fazer a mediação, entre o aprendiz e seus objetos de conhecimentos, utilizando alguns meios para auxiliar o método.

\section{REFERÊNCIAS}

ANTUNES, Celso. Onde esta a indisciplina? Existem três focos de incêndio a apagar. Petrópolis/RJ: Editora Vozes, 2002.

Aquino, J. G. Indisciplina: o contraponto das escolas democráticas. São Paulo: Moderna, 2003.

Indisciplina na Escola: alternativas teóricas e práticas. 2. ed. São Paulo: Sammuns, 1996.

BUSCAGLIA, L. Vivendo, amando e aprendendo. 15. ed. Rio de Janeiro: Record, 1993.

LOBATO, V. S. Concep̧̧ões de professores sobre questões relacionadas à 98 Olhar de professor, Ponta Grossa, Io(2): 81-99, 2007. REUNIÃO ANUAL DA ANPED, 29., 2006, Caxambu. Anais... Caxambu: ANPED, 2006.

PAPPA, J. S. A (in) disciplina e a violência escolar segundo a concepção de professores do ensino fundamental. 2004. Tese (Doutorado em Educação) - Faculdade de Filosofia e Ciências, Universidade Estadual Paulista, Marilia, 2004.

PIRES, Dorotéia Baduy. Disciplina: construção da disciplina consciente e interativa em sala de aula e na escola. Educação \& Sociedade, ano XX, no 66, Abril/99.

PIROLA, Sandra Mara Fulco. O problema da "indisciplina dos alunos": um olhar para as práticas pedagógicas cotidianas na perspectiva de formação continuada de professores. Olhar de professor, Ponta Grossa, Io(2): 8I-99, 2007.

SAMPA IO, Simaia. Mamual Prático do Diagnóstico Psicopedagógico Clínico. Rio de Janeiro: Wak, 201.

SANTOS, Claudevone Ferreira dos. A Indisciplina no cotidiano escolar. Candombá - Revista Virtual, v. 2, n. I, p. 14-23, jan - jun. 2006. 
VASCONCELlOS, Celso dos Santos. Disciplina: construção da disciplina consciente e interativa em sala de aula e na escola. São Paulo: Libertad, 1993.

TANZAWA, Elaine Cristina Livieiro; MARTINS, Juliana Grasiela Nunes; BENZAN, Sueli Gomes. Psicopedagogia Institucional: Passos para a Atuação do Assessor Psicopedagógico. Acesso em: in de Julho de 2013. 